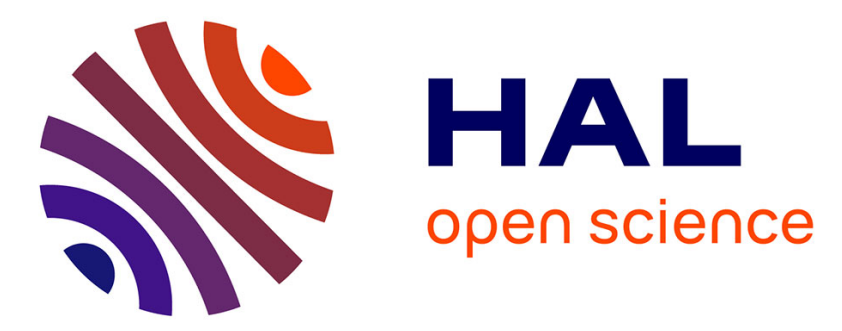

\title{
3D Thioether-Based Covalent Organic Frameworks for Selective and Efficient Mercury Removal
}

Yiying Zhang, Hui Li, Jianhong Chang, Xinyu Guan, Lingxue Q Tang, Qianrong Fang, Valentin Valtchev, Yushan Yan, Shilun Qiu

\section{To cite this version:}

Yiying Zhang, Hui Li, Jianhong Chang, Xinyu Guan, Lingxue Q Tang, et al.. 3D Thioether-Based Covalent Organic Frameworks for Selective and Efficient Mercury Removal. Small, 2021, 17 (22), pp.2006112. 10.1002/smll.202006112 . hal-03426048

\section{HAL Id: hal-03426048 https://hal.science/hal-03426048}

Submitted on 11 Nov 2021

HAL is a multi-disciplinary open access archive for the deposit and dissemination of scientific research documents, whether they are published or not. The documents may come from teaching and research institutions in France or abroad, or from public or private research centers.
L'archive ouverte pluridisciplinaire HAL, est destinée au dépôt et à la diffusion de documents scientifiques de niveau recherche, publiés ou non, émanant des établissements d'enseignement et de recherche français ou étrangers, des laboratoires publics ou privés. 
Three-Dimensional Thioether-Based Covalent Organic Frameworks for Selective and Efficient Mercury Removal

Yiying Zhang, Hui Li, Jianhong Chang, Xinyu Guan, Lingxue Tang, Qianrong Fang*, Valentin Valtchev, Yushan Yan, and Shilun Qiu*

Y. Zhang, H. Li, J. Chang, X. Guan, L. Tang, Prof. Q. Fang, Prof. S. Qiu,

State Key Laboratory of Inorganic Synthesis and Preparative Chemistry, Jilin University, Changchun 130012, P. R. China.

E-mail: qrfang@jlu.edu.cn or sqiu@jlu.edu.cn

Prof. V. Valtchev

Qingdao Institute of Bioenergy and Bioprocess Technology, Chinese Academy of Sciences, 189 Songling Road, Laoshan District, Qingdao, Shandong 266101, P. R. China

Prof. V. Valtchev

Normandie Univ, ENSICAEN, UNICAEN, CNRS, Laboratoire Catalyse et Spectrochimie, 6 Marechal Juin, 14050 Caen, France

Prof. Y. Yan

Department of Chemical and Biomolecular Engineering, Center for Catalytic Science and Technology, University of Delaware, Newark, DE 19716, USA 


\section{Abstract:}

Developing functionalized 3D covalent organic frameworks (3D COFs) is critical to broaden their potential applications. However, the introduction of specific functionality in 3D COFs remains a great challenge because most of the functional groups are not compatible with the synthesis conditions. Herein, for the first time 3D thioether-based COFs (JUC-570 and JUC-571) for mercury $\left(\mathrm{Hg}^{2+}\right)$ removal from aqueous solution is reported. These 3D thioether-based COFs prepared by the bottom-up approach display high $\mathrm{Hg}^{2+}$ uptakes $\left(972 \mathrm{mg} \mathrm{g}^{-1}\right.$ for JUC-570 and $970 \mathrm{mg}$ $\mathrm{g}^{-1}$ for JUC-571 at $\mathrm{pH}=5$ ), fast adsorption kinetics (distribution coefficient Kd value of $2.29 \times 10^{7} \mathrm{~mL} \mathrm{~g}^{-1}$ for JUC-570 and $2.07 \times 10^{7} \mathrm{~mL} \mathrm{~g}^{-1}$ for JUC-571), and favorable selectivity. In particular, JUC-570 is periodically decorated with isopropyl groups around imine bonds that markedly improve its chemical stability and effectively prevent the pore collapse, and thus endows high $\mathrm{Hg}^{2+}$ adsorption capacity (619 $\mathrm{mg}$ $\mathrm{g}^{-1}$ ) and excellent cycle performance even at $\mathrm{pH}=1$. This study not only puts forward a new route to construct stable functionalized 3D COFs, but also promotes their potential applications in areas related to the environment.

Keywords: covalent organic framework, mercury removal, selective adsorption, thioether functionalization 


\section{Introduction}

Covalent organic frameworks (COFs) are a type of burgeoning crystalline porous polymers constructed by organic building blocks regularly linked via strong covalent bonds. $^{[1]}$ Their high porosity, large surface areas, excellent chemical/thermal stabilities, and structurally adjustable reticular skeletonsare the basis of different applications, ${ }^{[2]}$ ranging from gas adsorption and separation, ${ }^{[3]}$ catalysis ${ }^{[4]}$ sensing,${ }^{[5]}$ optoelectronics, ${ }^{[6]}$ drug delivery, ${ }^{[7]}$ and many others. ${ }^{[8]}$ The introduction of specific functional groups in $\mathrm{COF}$ materials allows tailoring their interactions with guest species for the target application. To date, however, most of the applications were focused on the two-dimensional (2D) COFs with layered eclipsed stacking structures. By contrast, the exploration of three-dimensional (3D) COFs, is still extremely limited. ${ }^{[9]}$ This is mainly due to the related synthetic challenges, ${ }^{[10]}$ structural instability, ${ }^{[11]}$ narrow microporous channels, ${ }^{[12]}$ and complicated structure determination. ${ }^{[13]}$ In spite of these issues, 3D COFs have been considered as a powerful design platform for future applications. ${ }^{[1 \mathrm{f}]}$ We have recently reported some 3D functionalized COFs by elaborate pre-design, such as 3D ionic COFs for selective ion exchange, ${ }^{[14]}$ 3D Salphen-based COFs as catalytic antioxidants, ${ }^{[15]}$ 3D tetrathiafulvalene-based COFs for tunable electrical conductivity, ${ }^{[16]}$ and so on. ${ }^{[17]}$ It must be noted that the functionalization of 3D COFs still remains largely unexplored. Thus, the development of new 3D functionalized COF materials is vital to enrich the structural diversity and expand their potential applications. 
Mercury $(\mathrm{Hg})$ is one of the most harmful heavy metal due to its high toxicity, bioaccumulation, and persistence. ${ }^{[18]}$ Particularly, excessive $\mathrm{Hg}$ species in the environment will cause severe damages to human beings and other living organisms. Most $\mathrm{Hg}$ species exist in water in the form of $\mathrm{Hg}^{2+,}$ which can be easily converted to more toxic organic mercury species through biological activities. ${ }^{[19]}$ Consequently, the elimination of the $\mathrm{Hg}^{2+}$ from the water-body is a long-term global subject and an urgent stupendous challenge. Owing to the diversity of skeleton structure and pore chemical environment, COFs can be designed as functional target materials that are promising for handling environmental issues. Generally, there are two ways to achieve this goal, namely either the bottom-up approach ${ }^{[20]}$ or post-synthetic modification. ${ }^{[21]}$ However, the latter method has nonnegligible shortcomings, which including complicated procedure, ${ }^{[22]}$ structural breaking, ${ }^{[23]}$ and uncontrollable quantity of functional site. ${ }^{[24]}$ On the contrary, the above issues can be effectively avoided through the bottom-up approach that means the direct synthesis of COFs from pre-designed precursors with specific functional groups. At present, only some 2D COFs have been used for $\mathrm{Hg}^{2+}$ removal. ${ }^{[25]}$ Compared to $2 \mathrm{D}$ COFs with one-dimensional (1D) channels, 3D COFs not only feature more opening structures, but also possess numerous accessible, functional sites and higher surface areas, which are highly beneficial in $\mathrm{Hg}^{2+}$ adsorption. However, there is no related work has been reported yet.

Taking these issues into account, herein, we report 3D functionalized COFs (JUC-570 and JUC-571, JUC = Jilin University China), constructed from thioether 
functional units, 3,3",5,5"-tetraisopropyl-2',5'-bis((methylthio)methyl)[1,1':4',1"-terphenyl]-4,4"-diamine (TBTD) or 2',5'-bis((methylthio)methyl)[1,1':4',1"-terphenyl]-4,4"-dicarbaldehyde (BTD) by bottom-up approach. More importantly, JUC-570 was fully incorporated with isopropyl groups, which can effectively improve the chemical stability and avoid the pore shrinkage. Both COFs demonstrate high uptakes $\left(972 \mathrm{mg} \mathrm{g}^{-1}\right.$ for JUC-570 and $970 \mathrm{mg} \mathrm{g}^{-1}$ for JUC-571 at $\mathrm{pH}=5$ ), fast adsorption kinetics (distribution coefficient $K d$ value of $2.29 \times 10^{7} \mathrm{~mL}$ $\mathrm{g}^{-1}$ for JUC-570 and $2.07 \times 10^{7} \mathrm{~mL} \mathrm{~g}^{-1}$ for JUC-571), and excellent selectivity for $\mathrm{Hg}^{2+}$ ion. In particular, JUC-570 decorated with alkyl groups displays high $\mathrm{Hg}^{2+}$ adsorption capacity $\left(619 \mathrm{mg} \mathrm{g}^{-1}\right)$, and can be recycled at least four times at $\mathrm{pH}=1$. To the best of our knowledge, this study represents the first case of 3D thioether-based COFs by the bottom-up approach and their use for the removal of toxic heavy metal ion $\left(\mathrm{Hg}^{2+}\right)$.

\section{Results and Discussion}

\subsection{Structural Design}

Our strategy is based on the flexible thioether groups with small size, which likely possess the compatibility with the synthesis conditions of 3D COFs, and isopropyl groups around imine bonds in the framework that can increase the chemical stability of the material. As shown in Scheme 1, the tetrakis(4-formylphenyl)silane (TFS, Scheme 1a) and tetrakis(4-aminophenyl)methane (TAM, Scheme 1b) were designed as tetrahedral knots, and TBTD with isopropyl groups (Scheme 1c) or BTD without isopropyl groups (Scheme 1d) were chosen as two kinds of linear linkers. The 
condensation of TFS and TBTD or TAM and BTD resulted in JUC-570 (Scheme 1e) and JUC-571 (Scheme 1f). Linking $C 2$ and $T d$ symmetrical building units results in 3D networks with the dia topology (Scheme 1g). ${ }^{[26]}$ Owing to the tetrahedral centers separated by long linear linkers, the resulting structures tend to be interpenetrated networks. ${ }^{[27]}$

\subsection{Synthesis and Characterization}

3D thioether-based COFs were synthesized from TFS and TBTD or TAM and BTD under solvothermal reaction conditions in a mixture of 1,4-dioxane and mesitylene or a pure 1,4-dioxane in the presence of $6 \mathrm{M}$ acetic acid followed by heating at $120{ }^{\circ} \mathrm{C}$ for 3 days. Multiple characterizations were subsequently employed for their detailed structural definition. The morphology of both COFs was examined by scanning electron microscopy (SEM) (Figure S1) and transmission electron microscopy (TEM) (Figure S2), which revealed homogeneous ball shape for JUC-570 and rice shape for JUC-571, respectively. Peaks around $1643 \mathrm{~cm}^{-1}$ for JUC- 570 and $1624 \mathrm{~cm}^{-1}$ for JUC- 571 in Fourier transform infrared (FT-IR) spectra indicated the formation of $\mathrm{C}=\mathrm{N}$ bond. The concomitant disappearance of the N-H stretching vibration of TBTD (3490 3407 $\mathrm{cm}^{-1}$ ) and TAM (3395 3174 $\mathrm{cm}^{-1}$ ), as well as the $\mathrm{C}=\mathrm{O}$ stretching vibration of TFS $\left(1706 \mathrm{~cm}^{-1}\right)$ and BTD $\left(1696 \mathrm{~cm}^{-1}\right)$ gave a piece of direct evidence for the formation of imine linkages (Figures S3 and S4). Solid-state ${ }^{13} \mathrm{C}$ cross-polarization/magic-angle-spinning (CP/MAS) NMR spectroscopy further verified the presence of imine bonds by the peak at $162 \mathrm{ppm}$ for JUC-570 or $159 \mathrm{ppm}$ 
for JUC-571 (Figures S5 and S6). Thermogravimetric analysis (TGA) revealed that both COFs were stable up to about $350{ }^{\circ} \mathrm{C}$ under $\mathrm{N}_{2}$ atmosphere (Figures $\mathrm{S} 7$ and $\mathrm{S} 8$ ).

The crystallinity and unit cell parameters of 3D thioether-based COFs were determined by powder X-ray diffraction (PXRD) measurements and coupled with the structural simulation using Materials Studio software package (Figure 1). ${ }^{[28]}$ After the geometrical energy minimization, both COFs were set up based on a 10-fold interpenetrated dia net. Subsequently their unit cell parameters were acquired $(a=b=$ $30.2406 \AA, c=7.0039 \AA$ and $\alpha=\beta=\gamma=90^{\circ}$ for JUC-570; $a=b=28.8381 \AA, c=$ $7.1132 \AA$ and $\alpha=\beta=\gamma=90^{\circ}$ for JUC-571). Besides, the Pawley refinement yielded a PXRD pattern in which peaks at $4.38,6.19,6.92$, and $9.30^{\circ}$ for JUC-570 correspond to the (110), (200), (210), and (300) Bragg peaks of the space group P-4 (No. 81). Meanwhile, peaks at $4.41,6.25,7.01,8.87,12.62,17.86$, and $18.96^{\circ}$ for JUC-571 belong to the (110), (200), (210), (300), (400), (440), and (600) Bragg peaks of space group P-4 (No. 81). These results were in good agreement with the experimentally observed patterns, indicating by their negligible difference $(R \mathrm{wp}=2.90 \%$ and $R \mathrm{p}=$ $2.08 \%$ for JUC- 570; $R \mathrm{wp}=2.59 \%$ and $R \mathrm{p}=1.44 \%$ for JUC-571). It should be noted that a similar structure with 10-fold interpenetrated dia net (LZU-79) has been proved by a single crystal XRD analysis, and the PXRD patterns of JUC-570 and JUC-571 were well consistent with that of LZU-79 (Figures S9 and S10). ${ }^{[29]}$ On the basis of the above results, JUC-570 and JUC-571 were proposed to have the expected 10-fold interpenetrated dia topology, and the overall frameworks had 1D rectangular channels (Figure 2). The formation of highly interpenetrated structures is an expected 
consequence of the relatively long linear linkers employed. .The interpenetration of the linkers provides the low energy state necessary for the structural stability and generate huge diamond cavities. ${ }^{[17 c]}$

The nitrogen $\left(\mathrm{N}_{2}\right)$ adsorption-desorption isotherms were conducted at $77 \mathrm{~K}$ to evaluate the porosity of 3D thioether-based COFs (Figure 3). Both materials showed a sharp uptake at a low pressure of $\mathrm{P} / \mathrm{P}_{0}<0.05$, which fits the typical type I sorption model. The inclination of isotherms in the $0.8-1.0 \mathrm{P} / \mathrm{P}_{0}$ range and small hysteresis can be attributed to the presence of textural mesopores, which is a consequence of the agglomeration of COF crystals. ${ }^{[7 b]}$ The Brunauer-Emmett-Teller (BET) equation was carried out in the $0.05<\mathrm{P} / \mathrm{P}_{0}<0.30$ range, indicating BET specific surface area of $1227 \mathrm{~m}^{2} \mathrm{~g}^{-1}$ for JUC-570. Pore size distributions calculated by nonlocal density functional theory (NLDFT) showed micropores with a dominant size of $1.09 \mathrm{~nm}$ for JUC-570 (Figure 3a inset and Figure S11), which is in good agreement with that predicted from its crystal structure (1.17 nm for JUC-570). Obviously, under the support of isopropyl groups, JUC-570 effectively avoids the common breathing effect phenomenon in 3D COFs. ${ }^{[30]}$ By contrast, JUC-571 suffered from pore shrinkage after the solvent guests removal owing to the lack of isopropyl groups, which leads to lower BET specific surface area $\left(254 \mathrm{~m}^{2} \mathrm{~g}^{-1}\right)$ and pore size $(0.98 \mathrm{~nm}$, Figure $3 \mathrm{~b}$ inset and Figure S12). ${ }^{[31]}$

The chemical stabilities of 3D thioether-based COFs were also studied by exposure to different environments. As shown in Figure 4, JUC-570 still exhibited intense PXRD patterns after treated with $2 \mathrm{M} \mathrm{HCl}, 2 \mathrm{M} \mathrm{HNO}_{3}, 15 \mathrm{M} \mathrm{NaOH}$, boiling water, 
and common organic solvents for one week (Figure 4a and Figure S13), which indicates that its crystalline structure is well retained under these conditions. However, JUC-571 was not stable using diluted acid and base as $0.1 \mathrm{M} \mathrm{HCl}, 0.1 \mathrm{M} \mathrm{HNO}_{3}, 1 \mathrm{M}$ $\mathrm{NaOH}$, and boiling water for $24 \mathrm{~h}$, revealed by the PXRD analysis before and after the treatment (Figure 4b and Figure S14). Notably, the difference in chemical stability between two COFs can be attributed to the presence of isopropyl groups in the framework of JUC-571, which can effectively protect the hydrolytically susceptible backbones. $^{[30,32]}$

\subsection{Mercury Sorption Studies}

\subsubsection{Influence of $\mathrm{pH}$}

Giving the high porosity, excellent stability, abundant and accessible thioether arms of 3D thioether-based COFs, we conducted a sequence of systematic adsorption experiments to examine their adsorption ability of $\mathrm{Hg}^{2+}$ (Figure 5). The $\mathrm{pH}$ plays a key role in the adsorption process and affects the capture capacity of the adsorbents. ${ }^{[33]}$ Therefore, we first explored the effect of different $\mathrm{pH}$ values on the $\mathrm{Hg}^{2+}$ removal of 3D COFs. Because insoluble $\mathrm{Hg}(\mathrm{OH})_{2}$ can be formed at $\mathrm{pH}>6$, we explored the $\mathrm{pH}$ range of 1-6 for JUC-570. The pH range was limited between 2 and 6 for JUC-571 due to its unstable structure at $\mathrm{pH}=1$. I was found out that the optimal $\mathrm{pH}$ value for $\mathrm{Hg}^{2+}$ adsorption on 3D thioether-based COFs is 5 (Figure 5a). Both COFs showed reduced $\mathrm{Hg}^{2+}$ capture capacity at other $\mathrm{pH}$ values, since the adsorption process is related to the nature of $\mathrm{Hg}^{2+}$ species formed at different $\mathrm{pH}$ values. At lower $\mathrm{pH}$, the protonation effect on the surface of adsorbent, which produces electrostatic 
impediment repulsion with $\mathrm{Hg}^{2+}$ and superfluous $\mathrm{H}^{+}$, offers sorption competition with $\mathrm{Hg}^{2+}$, and thus prohibits further adsorption. ${ }^{[34]}$ At higher $\mathrm{pH}$ conditions, however, $\mathrm{Hg}^{2+}$ begins to undergo hydrolysis, reducing the adsorption amount of $\mathrm{Hg}^{2+} \cdot{ }^{[35]}$ Accordingly, a $\mathrm{pH}=5$ was considered as an optimum condition for subsequent experiments. It is worth noting that even at very low $\mathrm{pH}(\mathrm{pH}=1)$, the $\mathrm{Hg}^{2+}$ adsorption capacity of JUC-570 is still as high as $619 \mathrm{mg} \mathrm{g}^{-1}$.

\subsubsection{Adsorption Isotherms}

To evaluate the $\mathrm{Hg}^{2+}$ adsorption capacity of 3D thioether-based COFs, $\mathrm{Hg}^{2+}$ solutions with the initial concentrations in the range of $25 \sim 1000 \mathrm{mg} \mathrm{L}^{-1}$ were employed. After the experiment, the COF material was separated and the $\mathrm{Hg}$ concentration in the solution analyzed by ICP. As illustrated in Figure 5b, the adsorption capacity of both COFs increased significantly with the increase of the $\mathrm{Hg}^{2+}$ ion concentration driven by the concentration gradient force. The experimental maximum $\mathrm{Hg}^{2+}$ adsorption capacity of JUC-570 and JUC-571 was calculated to be $972 \mathrm{mg} \mathrm{g}^{-1}$ and $970 \mathrm{mg} \mathrm{g}^{-1}$, respectively, which ranks as one of the top values in most typical benchmark adsorbents, such as porous carbon $\left(518 \mathrm{mg} \mathrm{g}^{-1}\right),{ }^{[36]}$ TAPB-BMTTPA-COF (734 mg $\left.\mathrm{g}^{-1}\right),{ }^{[25 \mathrm{~b}]}$ Bio-MOF $\left(900 \mathrm{mg} \mathrm{g}^{-1}\right),{ }^{[37]}$ and PAF-1-SH $\left(1014 \mathrm{mg} \mathrm{g}^{-1}\right) .^{[38]}$ Both equilibrium adsorption isotherms were well-fitted with the Langmuir model that yields a correlation coefficient of 0.998 for JUC-570 (Figure S15) and 0.996 for JUC-571 (Figure S16). We reasoned that the outstanding capacity of JUC-570 stems from the synergistic effect of tremendous affinity between sulfur sites and $\mathrm{Hg}^{2+}$ together with high density and accessibility of thioether groups in inherent opening 
3D channels. In addition, their PXRD patterns revealed that both materials remained crystalline and structurally intact after adsorbing $\mathrm{Hg}^{2+}$ (Figures $\mathrm{S} 17$ and S18).

\subsubsection{Adsorption Kinetics}

To further reveal adsorption process, the adsorption kinetics of $\mathrm{Hg}^{2+}$ uptake was investigated in a system with $100.0 \mathrm{~mL}$ of $10.0 \mathrm{mg} \mathrm{L}^{-1} \mathrm{Hg}^{2+}$ and $5.0 \mathrm{mg}$ of 3D thioether-based COFs by measuring the $\mathrm{Hg}^{2+}$ concentration at different time. As shown in Figure 5c, JUC-570 can attain $99 \%$ of the adsorption capacity at equilibrium within $20 \mathrm{~min}$. from The fast adsorption kinetics of JUC-570 can be attributed to flexible short thioether chains, which is beneficial to expose sulfur sites and endows the channel of COFs maximum space. ${ }^{[22 b]}$ In comparison, the adsorption process of JUC-571 is relatively slow. This may be due to the breathing effect of JUC-571, and related slow rate of pore opening in the water. $\mathrm{Both} \mathrm{Hg}^{2+}$ adsorption data of $3 \mathrm{D}$ thioether-based COFs were well fitted with pseudo-second-order kinetic model, and the correlation coefficient as high as 0.9999 for JUC-570 and 0.9996 for JUC-571 (Figures S19 and S20). Distribution coefficient $(K d)$ represents an important index to evaluate the sorbent affinity to a metal ion, ${ }^{[25 b]}$ was calculated by the equation:

$$
K_{d}=\frac{C_{0}-C_{e}}{C_{e}} \times \frac{V}{m}
$$

Where $V$ is the volume of the treated solution $(\mathrm{mL}), m$ is the mass of adsorbent $(\mathrm{g}), C_{0}$ and $C_{e}$ are the initial and equilibrium concentration of $\mathrm{Hg}^{2+}$, respectively. Impressively, the $K d$ values of 3D thioether-based COFs were calculated to equal 2.29 $\times 10^{7} \mathrm{~mL} \mathrm{~g}^{-1}$ for JUC-570 and $2.07 \times 10^{7} \mathrm{~mL} \mathrm{~g}^{-1}$ for JUC-571, which can compare to most typical benchmark adsorbents for $\mathrm{Hg}^{2+}$ capture, including commercial resins (5.1 
$\left.\times 10^{5} \mathrm{~mL} \mathrm{~g}^{-1}\right),{ }^{[39]}$ TAPB-BMTTPA-COF $\left(7.82 \times 10^{5} \mathrm{~mL} \mathrm{~g}^{-1}\right),{ }^{[25 \mathrm{~b}]}$ Thiol-HKUST-1

$\left(4.73 \times 10^{5} \mathrm{~mL} \mathrm{~g}^{-1}\right),{ }^{[40]}$ and PAF-1-SH $\left(5.76 \times 10^{7} \mathrm{~mL} \mathrm{~g}^{-1}\right) .{ }^{[38]}$

\subsubsection{Selectivity}

Selectivity tests were performed in a mixed solution containing $\mathrm{Hg}^{2+}, \mathrm{Cu}^{2+}, \mathrm{Ca}^{2+}$, $\mathrm{Mg}^{2+}, \mathrm{Fe}^{2+}, \mathrm{Zn}^{2+}, \mathrm{Ni}^{2+}$ and $\mathrm{K}^{+}$for each concentration of $10.0 \mathrm{mg} \mathrm{L}^{-1}$ at $\mathrm{pH}=5$. As described in Figure 5d, both 3D thioether-based COFs could effectively remove $\mathrm{Hg}^{2+}$ and exhibited negligible capture capability for various nontoxic competitive ions. Therefore, the interference study indicated that 3D thioether-based COFs can remove $\mathrm{Hg}^{2+}$ from aqueous solutions selectively and effectively. The high selectivity is due to a strong affinity between sulfur and mercury since the equilibrium constant between the sulfur atom and mercury is significantly higher than between the sulfur other metals. $^{[41]}$

\subsubsection{Cycle Performance}

Cycle performance of the adsorbent is a critical index for cutting down the cost of the adsorption process in a practical application. 3D thioether-based COFs can be regenerated by treating with 1,2-ethanedithiol and used for cycle tests. As shown in Figure 5e, due to the high chemical stability, JUC-570 exhibited a similar $\mathrm{Hg}^{2+}$ removal efficiency after four successive experiments at $\mathrm{pH}=5$. However, under the same conditions, JUC-571 showed a gradually decreasing $\mathrm{Hg}^{2+}$ removal efficiency upon cycling test. It is worth mentioning that, even under the condition of $\mathrm{pH}=1$, JUC-570 can still retain 94\% removal efficiency after four cycles (Figure 5f). In 
addition, the crystallinity of reused 3D thioether-based COFs were negligible declined by PXRD analysis (Figure S21 and Figure S22). These results demonstrated that JUC-570 is robust enough, which make it a promising candidate in practical water remediation.

\subsubsection{Adsorption Mechanism}

To shed light on the adsorption mechanism staying behind the outstanding performance of $3 \mathrm{D}$ thioether-based COFs in mercury capture, we utilized ${ }^{13} \mathrm{C}$ CP/MAS NMR to figure out the interaction between $\mathrm{Hg}^{2+}$ and frameworks. The signals at $14.5 \mathrm{ppm}$ and $36.2 \mathrm{ppm}$ for JUC-570 (Figure S23, purple curve) and at 15.3 ppm and $35.7 \mathrm{ppm}$ for JUC-571 (Figure S24, green curve) were ascribed to the methyl carbon and methylene carbon adjacent to the $\mathrm{S}$ atoms. Upon the capture of $\mathrm{Hg}^{2+}$, the carbon signals were shifted to 18.4 ppm and 39.3 ppm for JUC-570 (Figure S23, pink curve) as well as $19.4 \mathrm{ppm}$ and $38.9 \mathrm{ppm}$ for JUC-571 (Figure S24, pink curve), respectively. At the same time, the imine-bond carbons and other signals were almost unchanged. These results pointed out that the flexible thioether groups interact with $\mathrm{Hg}^{2+}$ in both $3 \mathrm{D}$ thioether-based COFs. In contrast, the imine bonds played a limited role in the $\mathrm{Hg}^{2+}$ capture.

\section{Conclusion}

In conclusion, we rationally designed and synthesized two 3D thioether-based COFs JUC-570 and JUC-571, with 10-fold interpenetrated dia topology by the bottom-up approach. By introducing isopropyl groups around imine bonds, JUC-570 showed 
much higher chemical stability and BET specific surface area $\left(1227 \mathrm{~m}^{2} \mathrm{~g}^{-1}\right)$. Owing to the thioether functional groups in their frameworks, both COFs had high uptakes (972 $\mathrm{mg} \mathrm{g}^{-1}$ for JUC-570 and $970 \mathrm{mg} \mathrm{g}^{-1}$ for JUC-571 at $\mathrm{pH}=5$ ), high adsorption kinetics $\left(2.29 \times 10^{7} \mathrm{~mL} \mathrm{~g}^{-1}\right.$ for JUC-570 and $2.07 \times 10^{7} \mathrm{~mL} \mathrm{~g}^{-1}$ for JUC-571), and outstanding selectivity for $\mathrm{Hg}^{+}$ion. More important, JUC-570 displayed a high $\mathrm{Hg}^{+}$adsorption capacity (619 $\left.\mathrm{mg} \mathrm{g}^{-1}\right)$, and can be recycled at least four times underhighly aciiidic condions $(\mathrm{pH}=1)$ due to its excellent stability. This study not only established an efficient route to prepare stable 3D functionalized COFs, but also explored their application in the field of toxic metal decontamination.

\section{Experimental Section}

Synthesis of JUC-570: A Pyrex tube (volume: ca. $20.0 \mathrm{ml}$ with a body length of 18.0 cm) was charged with TBTD ( $21.76 \mathrm{mg}, 0.04 \mathrm{mmol}$ ) and TFS ( $8.96 \mathrm{mg}, 0.02 \mathrm{mmol}$ ) in a mixed solution of dioxane $(0.5 \mathrm{~mL})$, mesitylene $(0.5 \mathrm{~mL})$, and acetic acid $(0.2 \mathrm{~mL}$, $6 \mathrm{M})$. The tube was flash-frozen at $77 \mathrm{~K}\left(\mathrm{LN}_{2}\right.$ bath), evacuated to an internal pressure of $0.15 \mathrm{mmHg}$, and flame sealed. Upon sealing, the length of the tube was reduced to ca. $13 \mathrm{~cm}$. Upon warming to room temperature, the tube was heated at $120{ }^{\circ} \mathrm{C}$ for 3 days to afford a yellow precipitate, which was isolated by filtration and washed with acetone $(3 \times 5.0 \mathrm{ml})$ and yield of $75 \%$ for JUC-570. Annalitically calculated for $\mathrm{C}_{96} \mathrm{H}_{112} \mathrm{~N}_{4} \mathrm{~S}_{4} \mathrm{Si}:$ C: $96.00 ; \mathrm{H}: 7.64 ; \mathrm{N}: 3.79 ; \mathrm{S}: 8.67$; Si: 1.90. Found: C: 95.82; H: 7.69; N: 3.82; S: 8.69; Si: 1.85 .

Synthesis of JUC-571: In a manner similar to the preparation of JUC-570, a Pyrex tube (volume: ca. $20.0 \mathrm{~mL}$ with a body length of $18.0 \mathrm{~cm}$ ) was charged with BTD 
(16.24 mg, $0.04 \mathrm{mmol})$ and TAM $(7.6 \mathrm{mg}, 0.02 \mathrm{mmol})$ in a mixed solution of dioxane $(1.0 \mathrm{~mL})$ and acetic acid $(0.2 \mathrm{~mL}, 6 \mathrm{M})$. The tube was flash-frozen at $77 \mathrm{~K}\left(\mathrm{LN}_{2}\right.$ bath), evacuated to an internal pressure of $0.15 \mathrm{mmHg}$, and flame sealed. Upon sealing, the length of the tube was reduced to ca. $13 \mathrm{~cm}$. The reaction mixture was heated at $120{ }^{\circ} \mathrm{C}$ for 3 days to afford a yellow precipitate which was isolated by filtration and washed with acetone $(3 \times 5.0 \mathrm{ml})$ and yield of $82 \%$ for JUC-571. Annalitically calculated for $\mathrm{C}_{73} \mathrm{H}_{64} \mathrm{~N}_{4} \mathrm{~S}_{4}$ : C: 77.90; $\mathrm{H}$ : 5.73; N: 4.98; S: 11.39. Found: C: 77.95; H: 5.76; N: 4.89; S: 11.32 .

\section{Supporting Information}

Supporting Information is available from the Wiley Online Library or from the author.

\section{Acknowledgements}

This work was supported by National Natural Science Foundation of China (21621001, 21390394, and 21673094), "111" project (BP0719036 and B17020), and the program for JLU Science and Technology Innovative Research Team, and the Computing Center of Jilin Province for supercomputer time. V.V., S.Q. and Q.F. acknowledge funding from the French-Sino International Laboratory (LIA) "Zeolites".

\section{Conflict of Interest}

The authors declare no conflict of interest.

\section{Reference}

[1] a) A. P. Cote, A. I. Benin, N. W. Ockwig, M. O'Keeffe, A. J. Matzger, O. M. 
Yaghi, Science 2005, 310, 1166; b) H. M. El-Kaderi, J. R. Hunt, J. L. Mendoza Cortés, A. P. Côté, R. E. Taylor, M. O'Keeffe, O. M. Yaghi, Science 2007, 316, 268; c) X. Feng, X. Ding, D.-L. Jiang, Chem. Soc. Rev. 2012, 41, 6010; d) S.-Y. Ding, W. Wang, Chem. Soc. Rev. 2013, 42, 548; e) C. S. Diercks, O. M. Yaghi, Science 2017, 355, 1585; f) X.-Y. Guan, F.-Q. Chen, Q.-R. Fang, S.-L. Qiu, Chem. Soc. Rev. 2020, 49, 1357; g) X.-Y. Guan, H. Li, Y.-C. Ma, M. Xue, Q.-R. Fang, Y.-S. Yan, V. Valtchev, S.-L. Qiu, Nat. Chem. 2019, 11, 587.

[2] a) B. Dong, L.-Y. Wang, S. Zhao, R.-L. Ge, X.-D. Song, Y. Wang, Y.-N. Gao, Chem. Commun. 2016, 52, 7082; b) N. Huang, P. Wang, M. A. Addicoat, T. Heine, D.-L. Jiang, Angew. Chem., Int. Ed. 2017, 56, 4982; c) L.-H. Li, X.-L. Feng, X.-H. Cui, Y.-X. Ma, S.-Y. Ding, W. Wang, J. Am. Chem. Soc. 2017, 139, 6042; d) W. Cao, W.-D. Wang, H.-S. Xu, I. V. Sergeyev, J. Struppe, X. Wang, F. Mentink. Vigier, Z.-H. Gan, M.-X. Xiao, L.-Y. Wang, J. Am. Chem. Soc. 2018, 140, 6969; e) Y. Li, C.-X. Yang, H.-L. Qian, X. Zhao, X.-P. Yan, ACS Appl. Nano Mater. 2019, 2, 7290.

[3] a) S.-S. Han, H. Furukawa, O. M. Yaghi, W. A. Goddard Iii, J. Am. Chem. Soc. 2008, 130, 11580; b) P. Kuhn, M. Antonietti, A. Thomas, Angew. Chem., Int. Ed. 2008, 47, 3450; c) S. Wang, Q.-Y. Wang, P.-P. Shao, Y.-Z. Han, X. Gao, L. Ma, S. Yuan, X.-J. Ma, J.-W. Zhou, X. Feng, B. Wang, J. Am. Chem. Soc. 2017, 139, 4258 .

[4] a) S.-Y. Ding, J. Gao, Q. Wang, Y. Zhang, W.-G. Song, C.-Y. Su, W. Wang, J. 
Am. Chem. Soc. 2011, 133, 19816; b) X. Han, Q.-C. Xia, J.-J. Huang, Y. Liu, C.-X. Tan, Y. Cui, J. Am. Chem. Soc. 2017, 139, 8693; c) Y. Shi, X.-F. Zhang, H.-T. Liu, J.-Y. Han, Z.-J. Yang, L. Gu, Z.-Y. Tang, Small 2020, 16, 2001998.

[5] a) Z.-P. Li, Y.-W. Zhang, H. Xia, Y. Mu, X.-M. Liu, Chem. Commun. 2016, 52, 6613; b) C.-L. Zhang, S.-M. Zhang, Y.-H. Yan, F. Xia, A.-N. Huang, Y.-Z. Xian, Acs Appl. Mater. Inter. 2017, 9, 13415.

[6] a) S. Wan, J. Guo, J. Kim, H. Ihee, D.-L. Jiang, Angew. Chem., Int. Ed. 2009, 48, 5439; b) X. Feng, L. Chen, Y. Honsho, O. Saengsawang, L.-L. Liu, L. Wang, A. Saeki, S. Irle, S. Seki, Y.-P. Dong, Adv. Mater. 2012, 24, 3026; c) M. Dogru, M. Handloser, F. Auras, T. Kunz, D. Medina, A. Hartschuh, P. Knochel, T. Bein, Angew. Chem., Int. Ed. 2013, 52, 2920.

[7] a) L.-Y. Bai, S. Z. F. Phua, W. Q. Lim, A. Jana, Z. Luo, H. P. Tham, L.-Z. Zhao, Q. Gao, Y.-L. Zhao, Chem. Commun. 2016, 52, 4128; b) Q.-R. Fang, J.-H. Wang, S. Gu, R. B. Kaspar, Z.-B. Zhuang, J. Zheng, H.-X. Guo, S.-L. Qiu, Y.-S. Yan, J. Am. Chem. Soc. 2015, 137, 8352; c) B. Wang, X.-C. Liu, P.-W. Gong, X.-X. Ge, Z. Liu, J.-M. You, Chem. Commun. 2020, 56, 519.

[8] a) X.-S. Ding, J. Guo, X. Feng, Y. Honsho, J.-D. Guo, S. Seki, P. Maitarad, A. Saeki, S. Nagase, D.-L. Jiang, Angew. Chem., Int. Ed. 2011, 50, 1289; b) S. Chandra, T. Kundu, S. Kandambeth, R. BabaRao, Y. Marathe, S. M. Kunjir, R. Banerjee, J. Am. Chem. Soc. 2014, 136, 6570; c) Z.-B. Guo, Y.-Y. Zhang, Y. Dong, J. Li, S.-W. Li, P.-P. Shao, X. Feng, B. Wang, J. Am. Chem. Soc. 2019, 141, 1923. 
[9] a) G.-Q. Lin, H.-M. Ding, D.-Q. Yuan, B.-S. Wang, C. Wang, J. Am. Chem. Soc. 2016, 138, 3302; b) Y.-Z. Liu, Y-H. Ma, Y.-B. Zhao, X.-X. Sun, F. Gándara, H. Furukawa, Z. Liu, H.-Y. Zhu, C.-H. Zhu, K. Suenaga, P. Oleynikov, A. S. Alshammari, X. Zhang, O. Terasaki, O. M. Yaghi, Science 2016, 351, 365; c) Y.-B. Zhao, L. Guo, F. Gándara, Y.-H. Ma, Z. Liu, C.-H. Zhu, H. Lyu, C. A. Trickett, E. A. Kapustin, O. Terasaki, O. M. Yaghi, J. Am. Chem. Soc. 2017, 139, 13166; d) F. J. Uribe-Romo, J. R. Hunt, H. Furukawa, C. Klock, M. O’Keeffe, O. M. Yaghi, J. Am. Chem. Soc. 2009, 131, 4570.

[10] P. J. Waller, F. Gándara, O. M. Yaghi, Acc. Chem. Res. 2015, 48, 3053.

[11] S. Kandambeth, K. Dey, R. Banerjee, J. Am. Chem. Soc. 2018, 141, 1807.

[12] R.-M. Zhu, J.-W. Ding, L. Jin, H. Pang, Coordin. Chem. Rev. 2019, 389, 119.

[13] T.-Q. Ma, J. Li, J. Niu, L. Zhang, A. S. Etman, C. Lin, D. E. Shi, P. H. Chen, L.-H. Li, X. Du, J.-L. Sun, W. Wang, J. Am. Chem. Soc. 2018, 140, 6763.

[14] P. A. Kobielska, A. J. Howarth, O. K. Farha, S. Nayak, Coordin. Chem. Rev. 2018, 358, 92 .

[15] S.-C. Yan, X.-Y. Guan, H. Li, D.-H. Li, M. Xue, Y.-S. Yan, V. Valtchev, S.-L. Qiu, Q.-R. Fang, J. Am. Chem. Soc. 2019, 141, 2920.

[16] H. Li, J.-H. Chang, S.-S. Li, X.-Y. Guan, D.-H. Li, C.-Y. Li, L.-X. Tang, M. Xue, Y.-S. Yan, V. Valtchev, Q.-R. Fang, J. Am. Chem. Soc. 2019, 141, 13324.

[17] a) H. Li, Q.-Y. Pan, Y.-C. Ma, X.-Y. Guan, M. Xue, Q.-R. Fang, Y.-S. Yan, V. Valtchev, S.-L. Qiu, J. Am. Chem. Soc. 2016, 138, 14783; b) Q.-R. Fang, S. 
Gu, J. Zheng, Z.-B. Zhuang, S.-L. Qiu, Y.-S. Yan, Angew. Chem., Int. Ed. 2014, 53, 2878; c) X.-Y. Guan, Y.-C. Ma, H. Li, Y. Yusran, M. Xue, Q.-R. Fang, Y.-S. Yan, V. Valtchev, S.-L. Qiu, J. Am. Chem. Soc. 2018, 140, 4494; d) Q.-Y. Lu, Y.-C. Ma, H. Li, X-Y. Guan, Y. Yusran, M. Xue, Q.-R. Fang, Y.-S. Yan, S.-L. Qiu, V. Valtchev, Angew. Chem., Int. Ed. 2018, 57, 6042.

[18] a) H. H. Harris, I. J. Pickering, G. N. George, Science 2003, 301, 1203; b) W.-C. Li, H. Tse, Environ. Sci. Pollut. R. 2015, 22, 192.

[19] N. P. C. Maramba, J. P. Reyes, A. T. Francisco-Rivera, L. C. R. Panganiban, C. Dioquino, N. Dando, R. Timbang, H. Akagi, M. T. Castillo, C. Quitoriano, M. Afuang, A. Matsuyama, T. Eguchi, Y. Fuchigami, J. Environ. Manage. 2006, $81,135$.

[20] T. Xu, L. Zhou, Y. He, S.-H. An, C.-J. Peng, J. Hu, H.-L. Liu, Ind. Eng. Chem. Res. 2019, 58, 19642.

[21] S.-L. Ji, H.-L. Qian, C.-X. Yang, X. Zhao, X.-P. Yan, ACS Appl. Mater. Interfaces 2019, 11, 46219.

[22] Q.-Q. Yan, H.-J. Xu, X.-C. Jing, H. Hu, S.-L. Wang, C.-Y. Zeng, Y.-N. Gao, Rsc. Adv. 2020, 10, 17396.

[23] X.-F. Lu, W.-H. Ji, L. Yuan, S. Yu, D.-S. Guo, Ind. Eng. Chem. Res. 2019, 58, 17660.

[24] L.-L. Wang, H.-M. Xu, Y.-X. Qiu, X.-S. Liu, W.-J. Huang, N.-Q. Yan, Z. Qu, J. Hazard. Mater. 2020, 389, 121824.

[25] a) S.-Y. Ding, M. Dong, Y.-W. Wang, Y.-T. Chen, H.-Z. Wang, C- Y. Su, W. 
Wang, J. Am. Chem. Soc. 2016, 138, 3031; b) N. Huang, L.-P. Zhai, H. Xu, D.-L. Jiang, J. Am. Chem. Soc. 2017, 139, 2428; c) Q. Sun, B. Aguila, J. Perman, L. D. Earl, C. W. Abney, Y-C. Cheng, H. Wei, N. Nguyen, L. Wojtas, S-Q. Ma, J. Am. Chem. Soc. 2017, 139, 2786; d) X. Li, Y. Qi, G.-Z. Yue, Q.-X. Wu, Y. Li, M.-C. Zhang, X.-H. Guo, X.-F. Li, L.-J. Ma, S.-J. Li, Green. Chem. 2019, 21, 649 .

[26] O. Delgado-Friedrichs, M. O'Keeffe, O. M. Yaghi, Acta. Crystallogr. A. 2006, 62,350 .

[27] Y.-B. Zhang, J. Su, H. Furukawa, Y. Yun, F. Gándara, A. Duong, X. Zou, O. M. Yaghi, J. Am. Chem. Soc. 2013, 135, 16336.

[28] Materials Studio ver. 7.0; Accelrys Inc.: San Diego, CA.

[29] T.-Q. Ma, E. A. Kapustin, S. X. Yin, L. Liang, Z.-Y. Zhou, J. Niu, L.-H. Li, Y.-Y. Wang, J. Su, J. Li, X.-G. Wang, W.-D. Wang, W. Wang, J.-L. Sun, O. M. Yaghi, Science 2018, 361, 48.

[30] Y.-C. Ma, Y.-J. Wang, H. Li, X.-Y. Guan, B.-J. Li, M. Xue, Y.-S. Yan, V. Valtchev, S.-L. Qiu, Q.-R. Fang, Angew. Chem., Int. Ed. 2020, 59, doi.org/10.1002/anie.202005277.

[31] Y.-X. Ma, Z.-J. Li, L. Wei, S.-Y. Ding, Y.-B. Zhang, W. Wang, J. Am. Chem. Soc. 2017, 139, 4995.

[32] X.-W. Wu, X. Han, Y.-H. Liu, Y. Liu, Y. Cui, J. Am. Chem. Soc. 2018, 140, 16124.

[33] a) K. Li, J.-J. Li, N. Zhao, T.-T. Xie, B. Di, L.-L. Xu, Dalton. T. 2019, 48, 
17800; b) A. Hakimifar, A. Morsali, Inorg. Chem. 2018, 58, 180; c) F. Luo, J.-L. Chen, L.-L. Dang, W.-N. Zhou, H-L. Lin, J.-Q. Li, S.-J. Liu, M.-B. Luo, J. Mater. Chem. A 2015, 3, 9616.

[34] L. Esrafili, M. Gharib, A. Morsali, Dalton Trans. 2019, 48, 17831.

[35] J.-C. Cheng, Y.-F. Li, L. Li, P.-P. Lu, Q. Wang, C.-Y. He, New. J. Chem. 2019, 43, 7683.

[36] Y. Shin, G. E. Fryxell, W. Um, K. Parker, S. V. Mattigod, R. Skaggs, Adv. Funct. Mater. 2007, 17, 2897.

[37] M. Mon, F. Lloret, J. Ferrando-Soria, C. Mart-Gastaldo, D. Armentano, E. Pardo, Angew. Chem., Int. Ed. 2016, 128, 11333.

[38] B.-Y. Li, Y.-M. Zhang, D.-X. Ma, Z. Shi, S.-Q. Ma, Nat. Commun. 2014, 5, 5537.

[39] W. Yantasee, C. L. Warner, T. Sangvanich, R. S. Addleman, T. G. Carter, R. J. Wiacek, G. E. Fryxell, C. Timchalk, M. G. Warner, Environ. Sci. Technol. 2007, $41,5114$.

[40] F. Ke, L.-G. Qiu, Y.-P. Yuan, F.-M. Peng, X. Jiang, A.-J. Xie, Y.-H. Shen, J.-F. Zhu, J. Hazard. Mater. 2011, 196, 36.

[41] J. D. Merrifield, W. G. Davids, J. D. MacRae, A. Amirbahman, Water Res. 2004, 38, 3132 . 


\section{Figures and captions:}

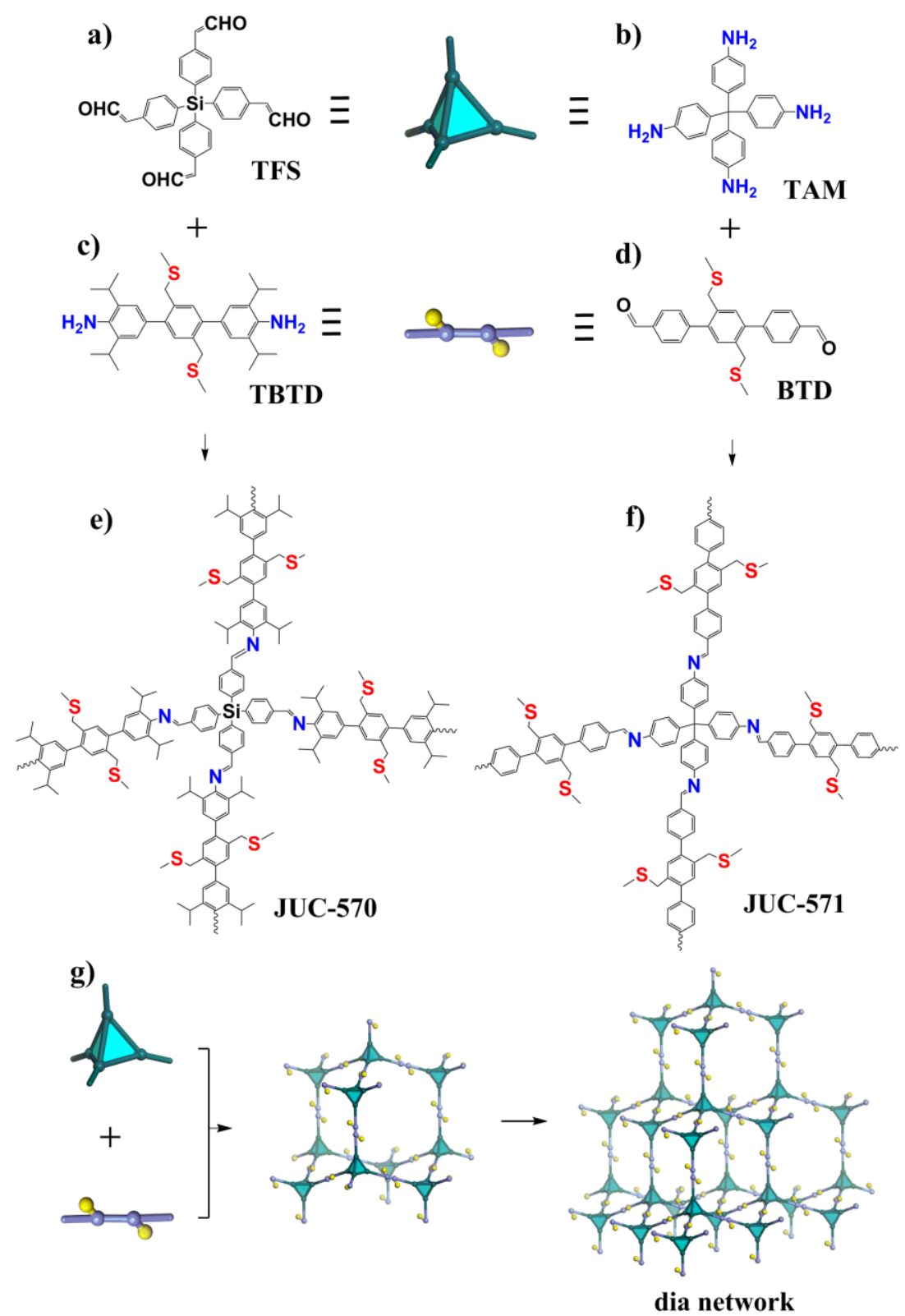

Scheme 1. Scheme of the strategy for preparing 3D thioether-based COFs. Molecular structures of TFS (a) and TAM (b) as tetrahedral building units, TBTD (c) and BTD (d) as linear building units. 3D thioether-based COFs denoted as JUC-570 (e) and JUC-571 (f), are constructed by the condensation reaction of TFS and TBTD, TAM and BTD. 
a)

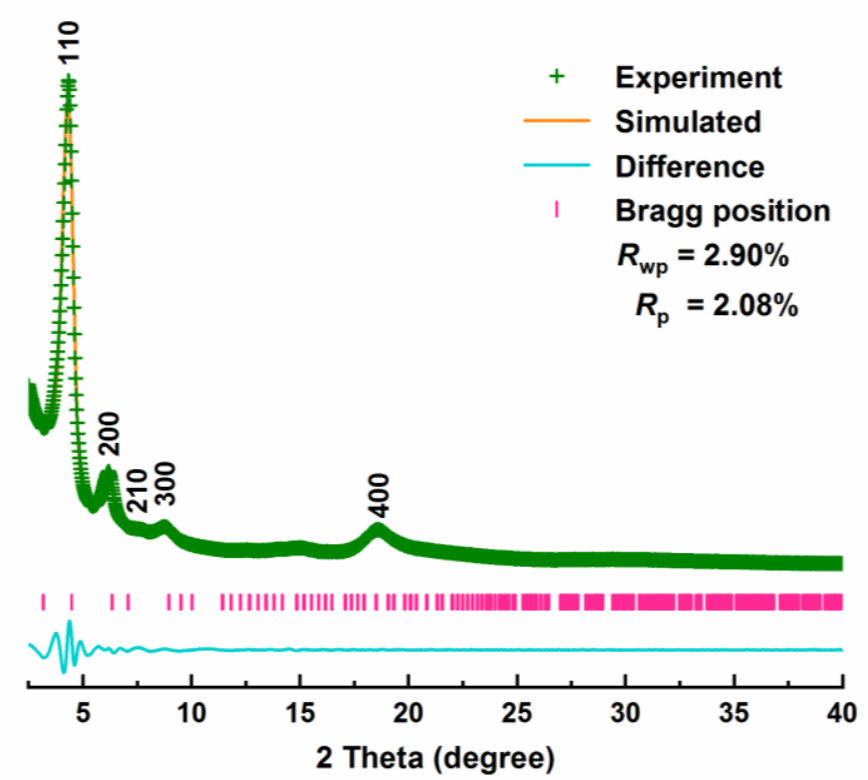

b)
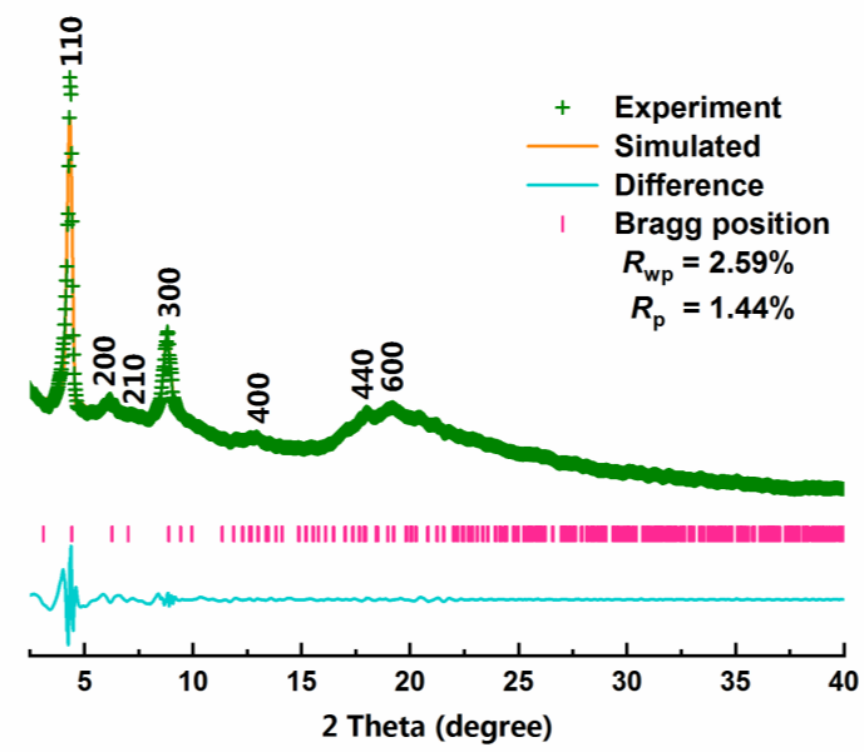

Figure 1. Experimental and refined PXRD patterns of JUC-570 (a) and JUC-571 (b). 


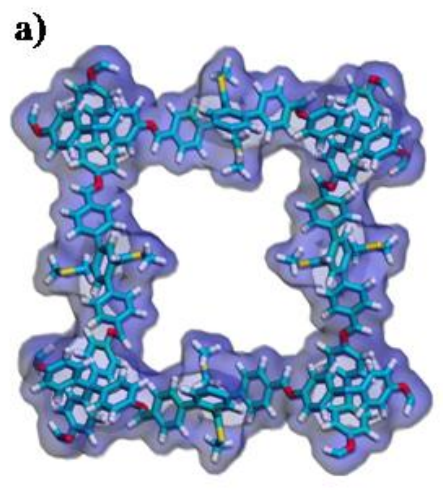

b)

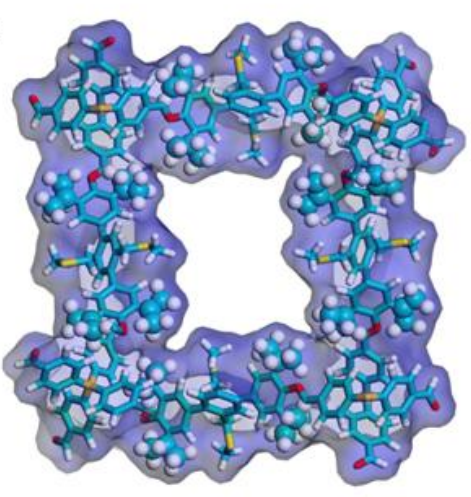

c)

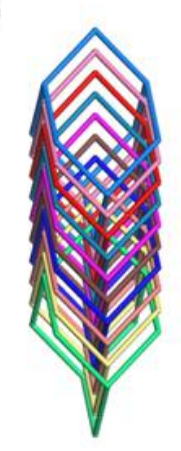

Figure 2. Extended structures of JUC-570 (a) and JUC-571 decorated with isopropyl groups (b). The 10-fold interpenetrated dia topology in JUC-570 or JUC-571 (c). 

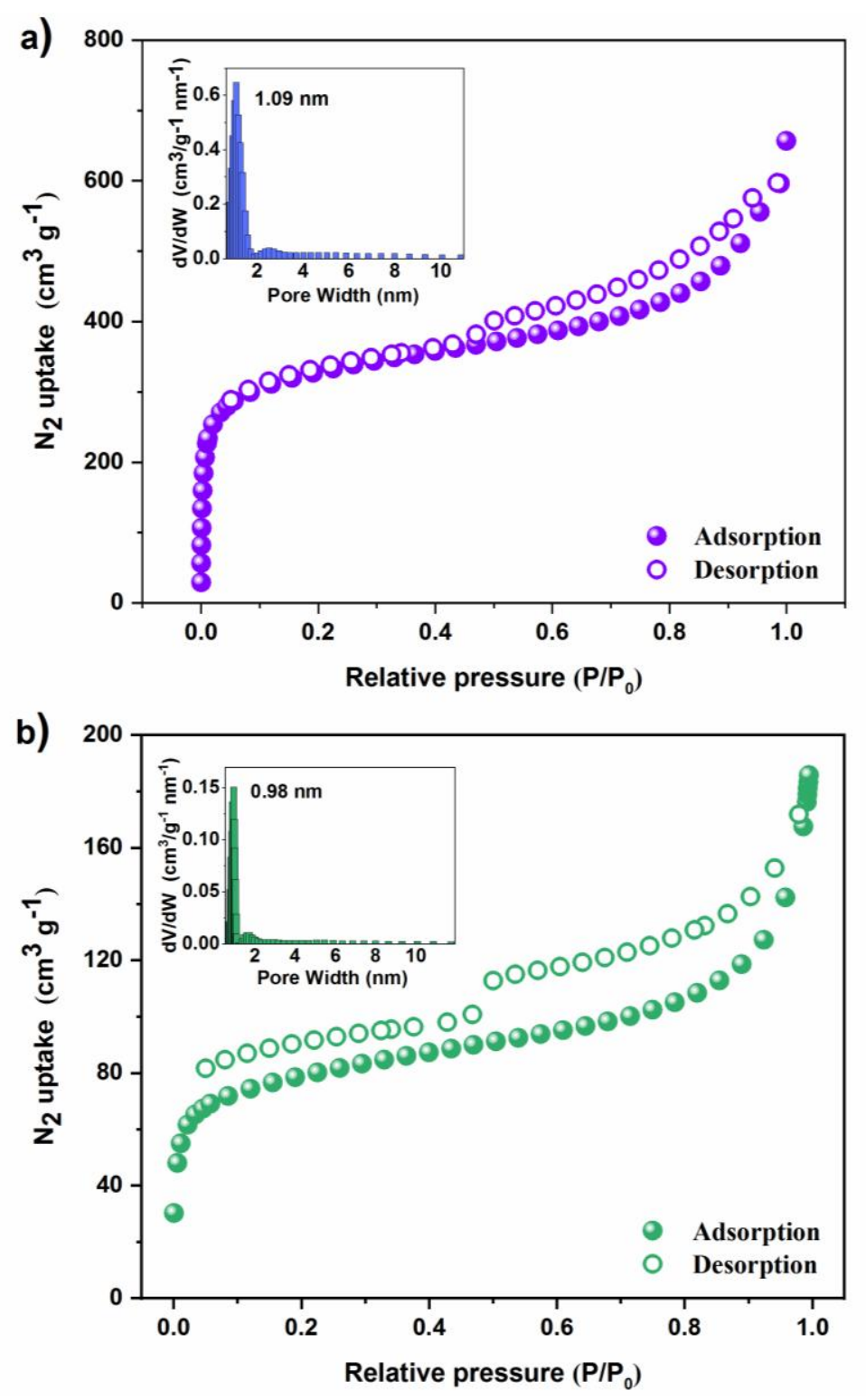

Figure 3. $\mathrm{N}_{2}$ adsorption-desorption isotherms for JUC-570 (a) and JUC-571 (b) at 77 K. Inset: pore-size distribution calculated by fitting on the NLDFT model to the adsorption data. 
a)

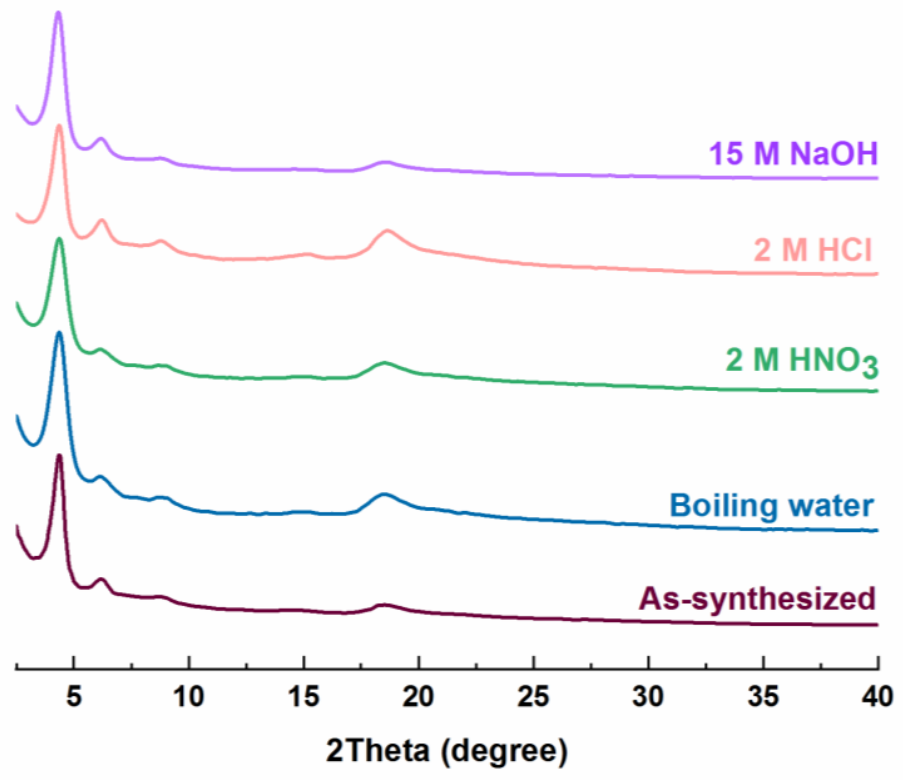

b)
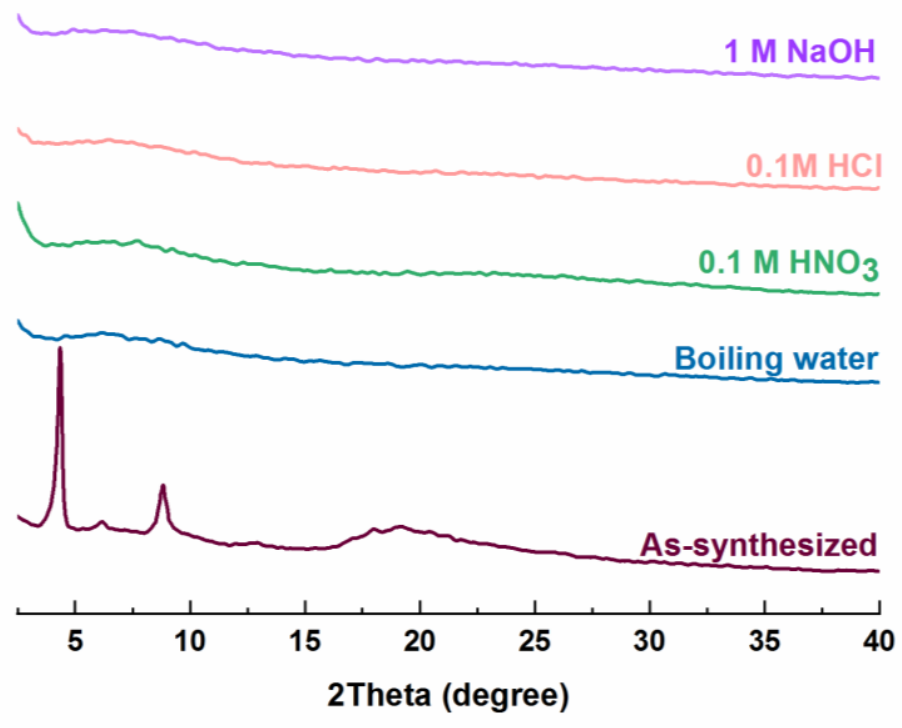

Figure 4. PXRD patterns of JUC-570 (a) and JUC-571 (b) after the treatment in strong acid, strong base and boiling water. 
a)

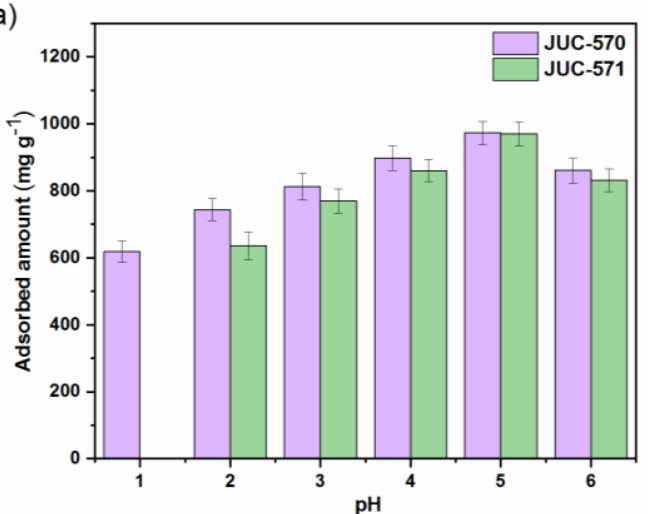

c)

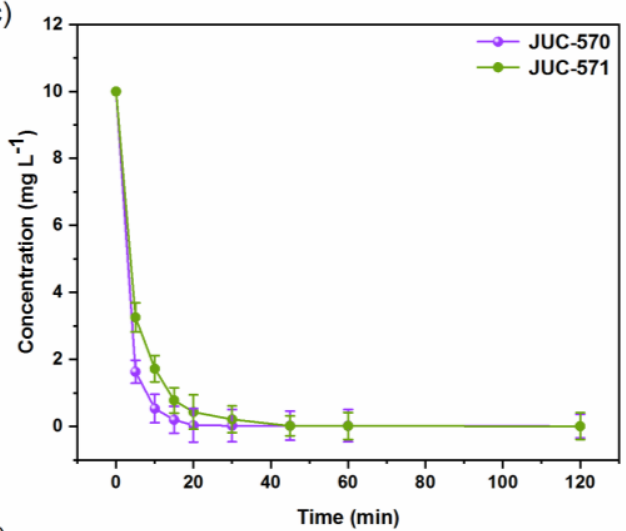

e)

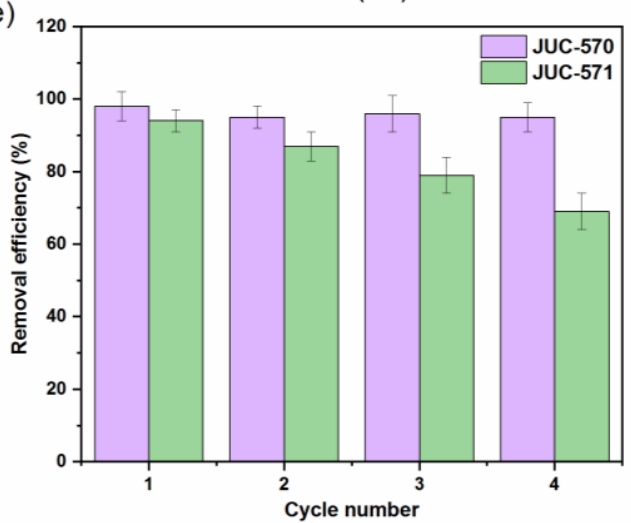

b)
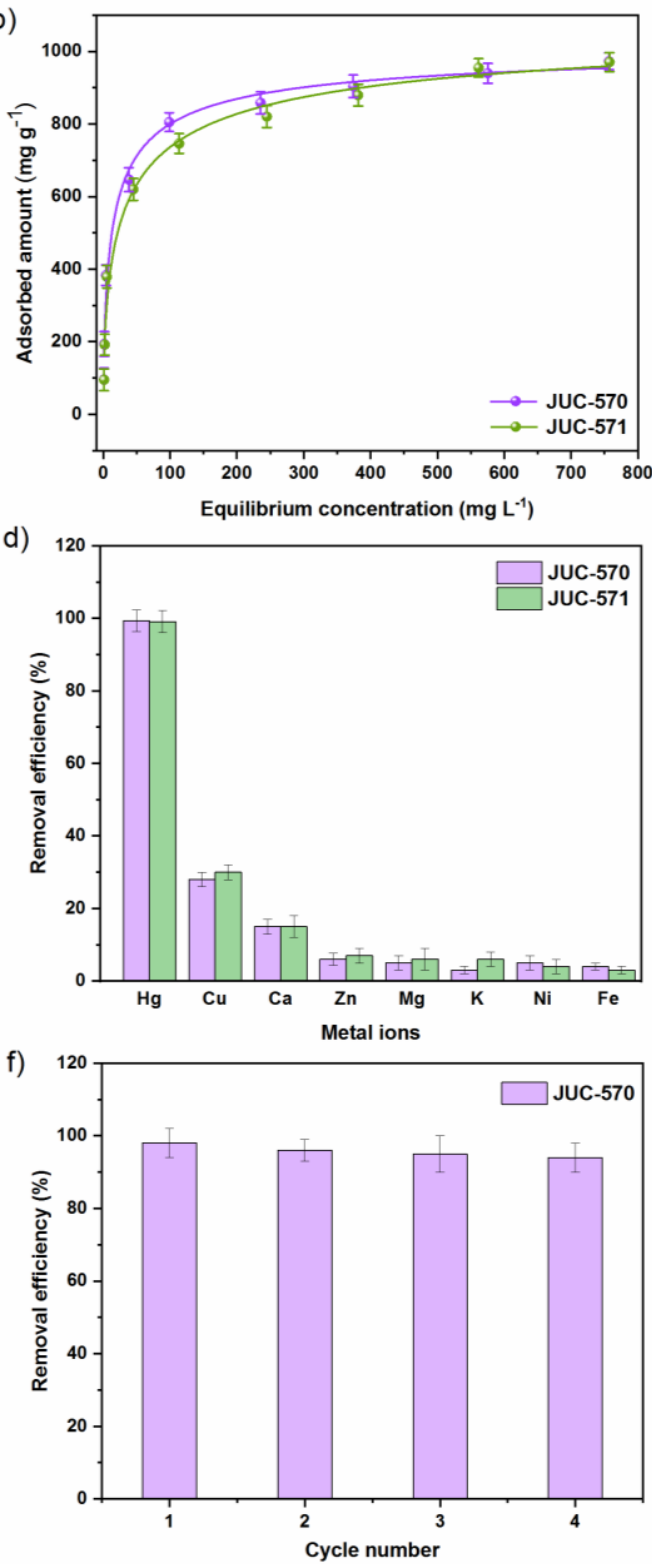

Figure 5. a) Effect of $\mathrm{pH}$ on the adsorption of $\mathrm{Hg}^{2+}$; b) $\mathrm{Hg}^{2+}$ adsorption isotherm of 3D thioether-based COFs at $\mathrm{pH}=5$ after $12 \mathrm{~h}$; c) $\mathrm{Hg}^{2+}$ sorption kinetics of 3D thioether-based COFs under the initial $\mathrm{Hg}^{2+}$ concentration of $10.0 \mathrm{mg} \mathrm{L}^{-1}$ and $\mathrm{pH}$ $=5$; d) Selectivity test of 3D thioether-based COFs in the mixed ion solution; e) Recycling test of 3D thioether-based COFs at $\mathrm{pH}=5$; f) Recycling test of JUC-570 at $\mathrm{pH}=1$. 


\section{ToC:}

Two 3D thioether-based COFs, JUC-570 and JUC-571, were for the first time prepared by the bottom-up approach, and used for mercury $\left(\mathrm{Hg}^{2+}\right)$ removal from aqueous solution. In particular, JUC-570 is periodically decorated with isopropyl groups around imine bonds, which displays higher chemical stability, BET specific surface area and $\mathrm{Hg}^{2+}$ removal performance.

Keywords: covalent organic framework, mercury removal, thioether functionalization

Yiying Zhang, Hui Li, Jianhong Chang, Xinyu Guan, Lingxue Tang, Qianrong Fang*, Valentin Valtchev, Yushan Yan, and Shilun Qiu*

Three-Dimensional Thioether-Based Covalent Organic Frameworks for Selective and Efficient Mercury Removal

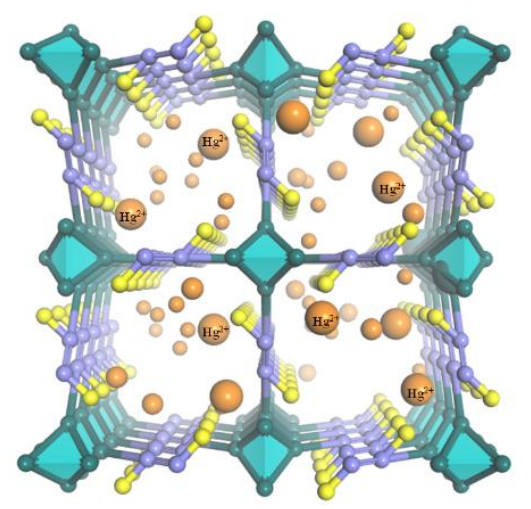

